\title{
Barriers to Implementing Research and Technology into the Rail Industry: A Case Study of TPWS and GSM-R in the United Kingdom
}

\author{
R. Welham and T. Fujiyama \\ Centre for Transport Studies \\ University College London, United Kingdom
}

\begin{abstract}
There is considerable pressure for the rail industry to deliver and implement technologies which increase the efficiencies of the railway. The Rail Technical Strategy Europe set out by the International Union of Railways (UIC) outlines what technologies are required to meet future demands. Research is key for such projects to develop, but there is an inherent issue of progressing the research through to the rail industry, with many barriers preventing their implementation. This paper has conducted two retrospective case studies on implementation in the UK; Train Protection Warning System (TPWS) and Global Systems for Mobiles - Railways (GSM-R). Performing a literature analysis has allowed this study to view how the research in the two cases developed, and by collecting qualitative data, analysis of the case studies around the topics of technology management, stakeholder management, and human factors from industry and technical experts, outlines the implementation approach taken. This paper uses the two cases to identify ways to overcome the barriers to implementation, and suggests that bridging the research-industry gap requires a more collaborative approach earlier in the research cycle to reduce the perceived risk of research and technology implementation, which in-turn increases its economic viability.
\end{abstract}

Keywords: implementation, research - industry, technology, management, stakeholders, human factors, TPWS, GSM-R

\section{Introduction}

The uptake of research into the UK rail industry has been a slow process, which has caused the general progression of the rail industry's technology uptake to be slow and for other transport industries to compete and overtake. With already high passenger numbers forecast to rise [1], it is imperative to understand where the barriers to 
implementation lie and how to overcome them. The UIC (International Union of Railways) has produced a document on the technology strategy for Europe, which outlines visions and objectives for certain aspects of the rail industry [2], a high-level document which does not provide much detail. The UK uses the Rail Technical Strategy 2012 [3], for a more detailed look at current rail visions and objectives.

Implementing research and technology has also been referred to as diffusion and implementation [4], technology diffusion and dissemination, technology transfer [5] or bridging the research-practice gap [6]-[9]. All variations are synonymous with their own specific contexts and cannot be applied to any specific need or requirement. Hameri [5] showed that pure collaboration between research and industry is not enough, and invariably does not exist. Greenhalgh et al. [10] conducted a systematic review of the literature and created a unifying model of the diffusion of innovations in health care, an industry which has a lot of focus in the area of implementation, with 'Implementation Science' being a term related solely to the health care industry [11]. Models and frameworks for dissemination and implementation reviewed by Tabak et al. [4] enables researchers to choose a model or framework that is right for their work, however, this is, again, mainly aimed for use in medicine and does not target use by any other industry. There are tools and techniques in current literature that are there to aid the implementation of research but they are mainly focused on other industries, such as health care [4], [10], [12]-[14], information technology in construction [15] and education [16]. These studies, give insights into the current academic work, which are aimed at the industries that they are focusing on, with little or no cross-over.

This paper creates a focus on the UK rail industry, with one of the case studies (Global Systems for Mobile-Railways, GSM-R), being a European Union (EU) initiative for interoperability [17]. Each country within the EU has different implementation strategies arising from their differing ownership models, i.e. some are state owned and others are part privately owned, like the UK [18]. Other industries and countries which face similar problems, and have similar levels of complexity, have differing methods to tackle such problems. The public sector in the UK has similar levels of complexity [19], such as health care, but have large research efforts based on the implementation of new working methods, technologies or procedures [18]. The UK energy sector has similar levels of stakeholder complexity to the rail industry and are subsidised government. Government legislation and subsidisation aids the implementation of technology, such as renewable energy, with incentives speeding up the development process [20], and as the development matures, the cost level of such technologies becomes economically attractive [21].

Very few industries or companies document implementation failures in literature, as this may result in damaging reputations [22]. However, many are quick to identify implementation successes, Enterprise Resource Planning (ERP) is an industry which is rich in literature on the factors affecting implementation [22]-[24], arising from its notoriously high implementation failure rate [22]. Other successful examples of implementation are found in manufacturing [25], but these studies offer little detail in what makes them successful and are specific to their niche context. 
Studies focusing on the implementation in the rail industry, such as Nash [26] and Wilson et al. [27], focus on implementing legislative reforms and specific ergonomic issues respectively. A recent study by Palacin et al. [28] identified the need to increase the uptake of innovations in the rail industry, focusing on barriers and enablers to implementation along technology readiness levels. Although much work has been carried out in the academic view of implementation, it has been specific to different industries other than rail. More studies are needed to understand how it can relate to the rail industry, and not only increase the uptake of research, but to then follow through the research to implementation.

Welham [29] stated that the UK rail industry can be identified as having three systems, 1) A stakeholder complex industry [30], and therefore a complex stakeholder system. 2) When developing technology, it becomes a very technical system. 3) When implementing said technology, there are humans that can aid or hinder that process, and can be referred to as a social system [29]. It is important when trying to implement research and technology into the rail industry, that it considers the three interlinking processes of stakeholder management, technology management, and human factors. This paper uses Welham [29], but outlines an approach to implement future research and technology into the UK rail industry, and shows that these three systems are an accurate way of portraying the implementation of research and technology.

Train Protection Warning System (TPWS) and GSM-R, which will be explained in Sections 3 and 4 in detail, are two industry wide projects that required the organisation of all the industry partners to implement the technology. Comparisons can be made between the two projects, with an outlining strategy on how to improve future research and technology implementation.

\section{Method}

The approach in this paper consists of two elements, a literature analysis, and interviews with industry experts. Both were used to develop two case studies on the projects of TPWS and GSM-R. The UK cases were chosen because information has been made publicly available, this is caused by the vertical separation in the UK, the UK railway is part publicly owned, meaning much of the information is required to be visible to the public. Comparing this to other countries, such as the US, where the railroad is highly privatised, this does not give the same levels of transparency that comes from the UK. This approach was also used to understand from both perspectives how the transfer from research to implementation was carried out. Palacin et al. [28] conducted a similar study using interviews as a method of data collection, and Kukafka et al. [31] performed a similar literature analysis to that of this study. The case study approach, similar to that of Thompson et al. [8] creates a structure that allows the combined method to be described in a structured manner. Using a combination of these study methods, with similar approaches, gives confidence that the study is comprehensive. 
The analysis of literature was undertaken to understand the research progression made during the development of each of the technologies. It researched relevant studies that aided the development of the technologies, academic and non-academic. Literature was analysed through a desk study, using current online data bases to search for materials relating to each project and their technologies. It also included those that built on basic research and those that were tailored for the specific technology. From this, graphical representations of how research progressed, and at what point the technology was introduced within the research cycle, have been made. Table 1 shows the typical types of persons interviewed. Research on the background of the interviewee was conducted to formulate appropriate question guides. This ensured the data collected was accurate and relevant to their experience and knowledge. Semistructured questions were based around the stakeholder management, technology management, and human factors of the projects.

\begin{tabular}{lll}
\hline Organisation Type & Typical Roles & Initials \\
\hline Advisory Groups & Head of Major Projects & P. B / N. O \\
European Governing Body & Engineer & D. M \\
Infrastructure Manager & Chief Engineer & C. B \\
Train Operator & Project / Engineering Manager & K.V / H.C \\
Train Owner & Special Projects Manager & A. S \\
\hline
\end{tabular}

Table 1: Typical roles and organisations of interviewees

The information given has then been used to formulate the case study. No direct quotes were used, all interviews have been recorded and transcribed. The results of each case study are compiled from the responses of the interviewees and from the relating literature.

\section{Train Protection Warning System}

\subsection{Background}

Train Protection Warning System (TPWS) is a signalling safety system fitted to the UK railway to prevent SPAD's (Signal Passed at Danger), and prevent over speeding at certain locations, and to accommodate the shortcomings of the Advanced Warning System (AWS) [32]. TPWS works in two parts; one piece of technology on the train, another as part of the infrastructure. Therefore, for this project to be implemented successfully, it needed to bring together multiple stakeholders across the industry.

The whole project was delivered on time and on budget and brought the biggest safety improvement since AWS. Over 12,000 signals, 650 buffer stops, 1000 speed limits and 6000 types of rolling stock, had all been fitted with TPWS within a 3-year timeline [33]. The Railway Safety Act 1999 mandated it to be fully operational by 
the $1^{\text {st }}$ January 2004. TPWS was recommended to be implemented after the Southall train crash in West London in 1997, where 7 people died and 150 were injured [34]. Automatic Train Protection (ATP), as called for after the Clapham Rail disaster in 1988 , was estimated to cost $£ 1$ bn [35]. TPWS was announced to be the preferred train protection system in 1999, and would cost around $£ 150 \mathrm{~m}$ to install. TPWS was chosen over ATP as it would be $10-15 \%$ of the cost, installed in a quarter to a third of the time, and provide $70 \%$ of the safety capability [34]. This was welcome news for some, but unwelcome for others. Unions were happy that a protection system was to be implemented, but their concern was that they believed cost was being put before safety. Mick Rix, the General Secretary of ASLEF, stating at the time "TPWS would catch two thirds of trains passing red signals" [35].

\subsection{Results}

\subsubsection{Knowledge progression}

The research carried out that formed the base of TPWS started back in the early 90's when research was being conducted by British Rail on the development of ATP. After ATP was deemed to be too expensive, work started on the SPADRAM (SPAD Reduction and Mitigation) project [36]. It can be seen in Figure 1 via the dashed line, the point at which the SPADRAM project started. The studies used previous knowledge developed from research on ATP to produce technical specifications for the reduction of SPADS [37], and that TPWS would incorporate and build on AWS in its design $[12,13]$. Once implemented, the number of studies stopped altogether until problems arose that needed investigating. Figure 1 shows 24 studies were carried out in developing TPWS (including those done on ATP) by the time of implementation. The most likely increase in the speed of implementation from the main study phase was as a result of the Ladbroke Grove incident in 1999 [39].

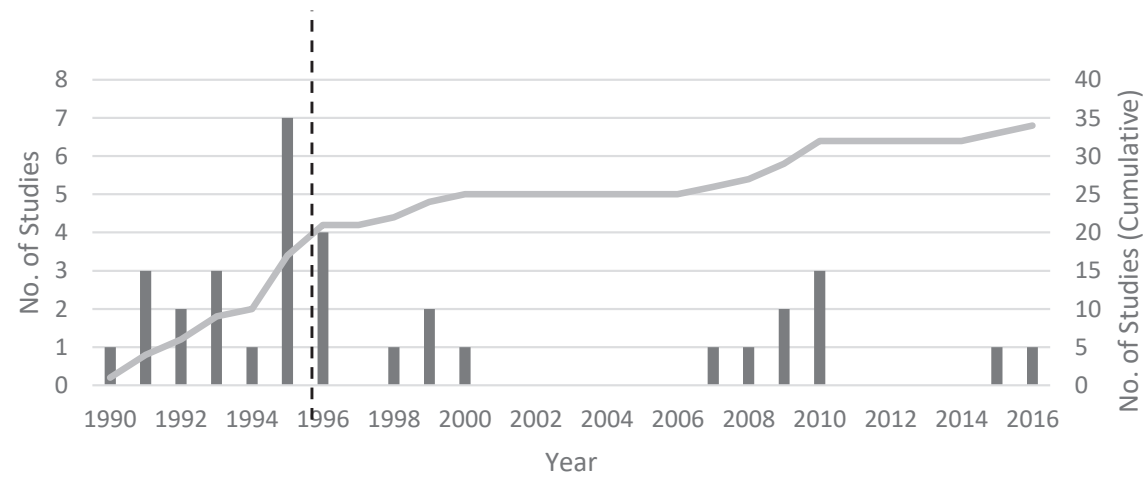

No. of Studies Cumulative Total

Figure 1: The number of studies conducted on the development of TPWS 
Figure 1 shows a spike in knowledge peaking early and implementation starting shortly after, inferring that the motive to ensure a safer railway caused the increase in productivity. Once the implementation was started, the 1999 Safety Regulation Act, a deadline implicated by law, created more pressure on those working on the project.

\subsubsection{Technology management}

The technology management for TPWS was relatively simple for an industry wide project, (A.S Personal Communication) with a tendering process and trials (Table 2), with several suppliers used in the development of the product who already had substantial experience in train protection technology [38].

\begin{tabular}{ll} 
Year & Event \\
\hline 1995 & $\begin{array}{l}\text { 12 Companies invited to tendering process } \\
\text { Redifon were chosen as the preferred supplier }\end{array}$ \\
\hline $\mathbf{1 9 9 6}$ & $\begin{array}{l}\text { Railtrack appointed Redifon to design and supply the equipment } \\
\text { AEA Technologies \& W. S Atkins commissioned to aid with design } \\
\text { evaluation and development }\end{array}$ \\
\hline $\mathbf{1 9 9 7}$ & Trials started 26 Oct 1 month after Southall train crash \\
\hline $\mathbf{1 9 9 8}$ & Trials extended to address further technical developments \\
\hline $\mathbf{1 9 9 9}$ & Implementation started \\
\hline $\mathbf{2 0 0 3}$ & Implementation finished \\
\hline
\end{tabular}

Table 2: Timeline of TPWS development (developed from Uff \& Cullen [38] and interviews)

The implementation of TPWS to the rolling stock was paid for and implemented by the Rolling Stock Leasing Companies (ROSCO's). This was enabled by the agreement put in place at the break up of British Rail when the ROSCO's were formed (A.S Personal Communication). This meant funding of the project was made simple and did not create disagreements from other stakeholders who might not want to fund the project. After discussions with the infrastructure manager, the TPWS deployment plan was rolled out as separate elements (A.S Personal Communication), arising from the two systems (both on track and on train) working independently of each other until the systems were synchronised. It meant that in-depth, complex planning was not necessary to align the two systems simultaneously.

The deployment of the technology to the rolling stock on the Train Operating Companies (TOC) side was relatively simple. The trains were taken out of service and fitted with the equipment (P.B Personal Communication). The supplier (Redifon) was employed as turnkey contractors and responsible for liaising with the operators to develop a fitment plan for the trains. This plan was agreed with all parties concerned and used to monitor the progress of the turnkey contractor in the 2-year window given to retro-fit the equipment (A.S Personal Communication). 
Once the implementation was complete, there were a few operational issues at the beginning, one of which was the issue of 'reset and continue' (P.B Personal Communication). Drivers, who had passed a signal at danger, would reset the TPWS and continue without confirmation from the signaller that it was safe to do so. Research by the RSSB [40]-[43] on this issue can be seen by the studies carried out in 2007 to 2010 in Figure 1.

Another problem was with approaching buffer stops into the station platform, the speed on the system was set too low, causing the breaks to be applied. This, then caused passengers to attempt to open doors where it may have been unsafe to do so. This was quickly rectified and the speed increased (P.B Personal Communication). Another issue that occurred were complaints from drivers on approaching PSR's (Permanent Speed Restrictions) where there was a brake application. This caused many discussions between the infrastructure manager and the TOC's to resolve the issue [44]. Signs of evaluation of the technology is evident, but, it was only to resolve any issues that arose from the implementation. It was deemed a success because it worked.

\subsubsection{Stakeholder management}

Most main stakeholders were involved during the design process of the TPWS system: drivers were consulted, along with unions, to establish the location of the equipment in the cab (P.B Personal Communication); with operators and ROSCO's working together to determine the detailed design of the equipment for each class of train. The stakeholder complexity in this case was relatively low, as a result of the Railway Safety Regulations Act 1999, the implementation of TPWS was made a legal requirement (P.B Personal Communication).

End users of TPWS, i.e. train operators, drivers, staff, were made aware of the introduction of TPWS when the Railway Safety Regulations Act 1999 was created. In most cases the industry acted as individuals rather than as a collective ( $P . B$ Personal Communication).

Shortly after the complete implementation of TPWS in early 2004, the TPWS Strategy Group was set up as part of the V/TCC SIC (Vehicle/Train Control and Communications Systems Interface Committee, which is now the TPSG (Train Protection Strategy Group (P.B Personal Communication).

Stakeholders were kept up to date with the information that concerned them, such as; to which signals the system would be fitted, and, when they would be fitted. This meant there would be no unnecessary time wasted relaying information to stakeholders that was not relevant (P.B Personal Communication). For the first time, the three rolling stock leasing companies Eversholt, Angel Trains, and Porterbrook, created a contract between themselves to work together. The reason for this was not only economies of scale, making a single design for a single class of train, but also for the overall benefit to the industry (A.S Personal Communication). Providing a single 
supplier with a single point of contact, made it easier in terms of communicating between stakeholders, ensuring the supplier was compliant, and making sure that they took responsibility for the risk of the work (A.S Personal Communication).

Redifon, the supplier of the TPWS train equipment, was also responsible for communicating with the operating companies to create a vehicle release plan, taking certain vehicles out of service ready for installation (P.B Personal Communication).

\subsubsection{Human factors}

In 2008, the Rail Safety Standards Board (RSSB) published a document on understanding Human Factors in the Railway [45]. This document describes human factors involving design, training, staffing, conditions and culture-organisational behaviour.

Arising from the interaction between human and machine, the design and location of the cab equipment was critical and involved a human factors study (A.S Personal Communication). This paper will focus more on the other aspects of human factors described in the RSSB document [45], as behavioural and cultural reaction to implementation has a greater impact [46]. For TPWS, human factors were a minimal part of the project. It was implemented via law, which meant that there was very little, if any resistance to the project. Therefore, the cultural behaviours towards a new technology were not extensively thought through (P.B Personal Communication). However, the change that was brought into the industry, and affected people working with it, still had to be managed.

As the ROSCO's had agreed to work together on this project, a contractual agreement was made, that included a certain organisational structure to be put in place, shown in Figure 2.

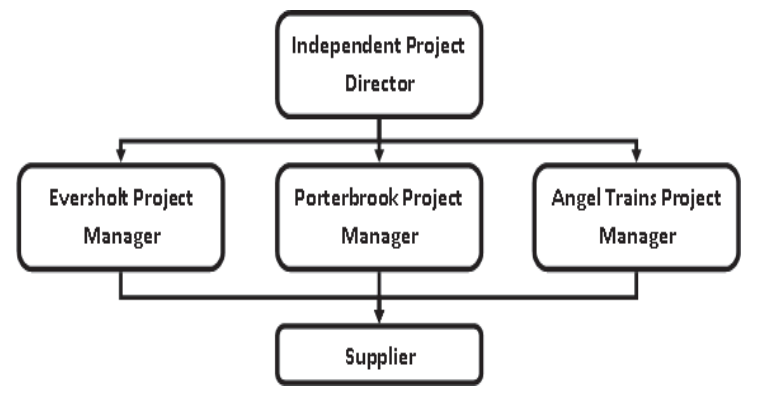

Figure 2: Organisational structure of the ROSCO's (A.S Personal Communication)

This change process was an internal agreement for the mutual benefit of all parties involved. The independent project director meant that no bias was given to a particular leasing company and meant integrity between the three ROSCO's was maintained (A.S Personal Communication). 
Operational training was provided by the suppliers (A.S Personal Communication) and a standard package of training given to each driver (P.B Personal Communication). The supplier would train a trainer from each TOC, who would then disseminate the information and proficiency to the drivers. This training was not too overcomplicated and took around a day to complete (P.B Personal Communication). For the maintenance staff, an updated version of the specifications was given to them, detailing what to check and when, with associated fault finding instructions (A.S Personal Communication).

\section{Global Systems for Mobiles - Railway}

\subsection{Background}

GSM-R provides a platform for data communication between the train and the operational infrastructure [47] and replaced the analogue radio, known as the National Radio Network (NRN) [48]. GSM-R is a piece of equipment installed in the cab of the train and as part of the infrastructure, so the driver can communicate with the signaller and vice versa.

According to Network Rail [49], there are two main reasons why GSM-R was introduced: 1) To comply with the European standard for digital data and voice communications; 2) To follow recommendations from major incident enquiries. With the added benefits of increased safety, improved performance, enhanced passenger experience and preparation for the 'digital future'. Benefits of GSM-R in the UK have been listed by Maxwell et al. [50] as a modern digital upgrade adapted for the railway, with improved reliability, availability, and voice quality. It enables fast response to emergency calls and is also the data bearer for ETCS (European Train Control System) levels 2 and 3, allowing the transmission of information signals between network interfaces.

\subsection{Results}

\subsubsection{Knowledge progression}

The research progression in the case of GSM-R grew slowly, Figure 3 shows this progression, with the dashed line showing when the UK decided to adopt the European standard [51]. With much of the research for GSM-R being done in Europe and inside the International Union of Railways (UIC). Figure 3 is a general overview of the studies relating to the development and does not constitute an accurate representation.

In 1997 the trials in Europe started, and therefore some papers were published by Wheldon [37] and Uff \& Cullen [38] with the results of the trials. Studies carried out on merging telecommunication and signalling [52], and problems of interference [53]. 


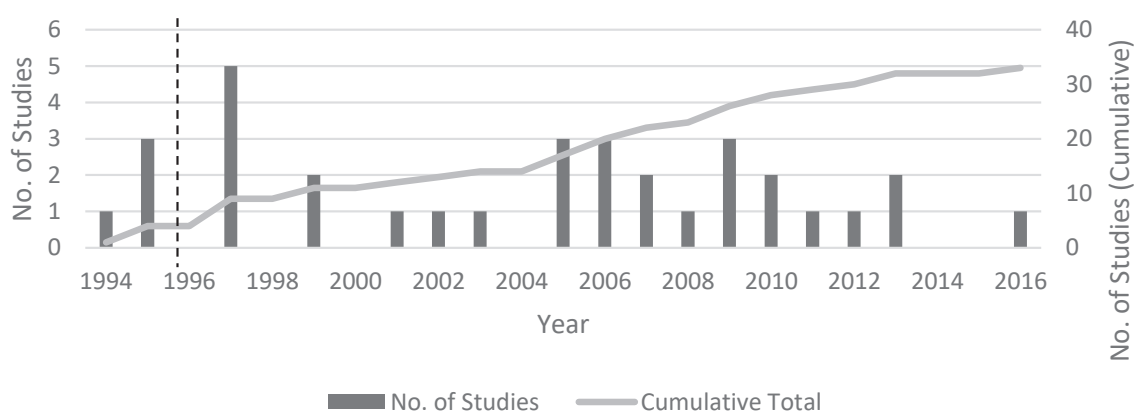

Figure 3. Graph showing the number of studies conducted on the development of GSM-R before and after implementation

\subsubsection{Technology management}

In 1993, the UIC selected GSM (Global Systems for Mobiles) as a basis for the future integrated digital radio system called EIRENE [54]. The EIRENE specifications were finalised in 1995 (D.M Personal Communication). These specifications were then validated through three pilot lines in Florence, Stuttgart, and Paris, involving GSM suppliers willing to support GSM-R [55]. From these test results, it was shown that although the three systems from the three test lines were not connected to one another, the mandatory functions could be implemented and tested [55].

\begin{tabular}{ll} 
Year & Event \\
\hline 1993 & GSM chosen as the technology for digital radio system \\
\hline $\mathbf{1 9 9 5}$ & Technical specifications completed by the UIC \\
\cline { 2 - 2 } & Railtrack initiated study into options for replacement of radio systems \\
\hline 1996 & MORANE trials carried out in Germany, France \& Italy \\
\hline $\mathbf{1 9 9 9}$ & Four-year study completed by the UIC \\
\hline $\mathbf{2 0 0 7}$ & UK Strathclyde trials began \\
\hline $\mathbf{2 0 0 9}$ & Extended trials \\
\hline $\mathbf{2 0 1 0}$ & Implementation started \\
\hline
\end{tabular}

Table 3: Timeline of GSM-R Development

In 2007, the UK conducted trials in Strathclyde, Scotland. The first route, Route A was a 53 mile route with $50 \%$ of train services using GSM-R, and, in 2008, Route $\mathrm{B}$, a 17 mile route with three manual signal boxes was introduced [56]. The trials were conducted to confirm the design of the radios and fixed terminal dispatcher system and to test the procedures and processes [56]. Rules and regulations were also developed during the trial and written by the RSSB [57]. 
The lessons learnt from the Strathclyde trials however, were not all acted upon, which made certain aspects of the technology difficult to deal with, for example, the Disc-On-Module (digital storage for use with electronics) in the radio unit was changed as a result of a reliability issue. This caused problems because it was then not properly tested (P.B Personal Communication).

The radios were designed against the original train drawings, and in some cases, the age of the rolling stock caused a problem, with much of the older stock being modified and no longer accurate to the original drawings. This created a lack of locations in which the radios could be fitted to the train cabs (K.V Personal Communication).

The roll-out plan was designed by the Network Rail project team but was found to be more complex than first thought. The struggle that Network Rail had was not with the technology but with the integration of the technology and the complex data driven system. The data, kept in seven different databases, swamped Network Rail as they did not know how to produce the data in a manageable format (P.B Personal Communication).

Once GSM-R was initially rolled-out, the performance of the railway dropped, with delays attributed to the new system (P.B Personal Communication). To combat this, and to manage the data better, Network Rail created Project ARTEMIS [58]. Project ARTEMIS involved the whole industry and was set up to allow stakeholders to perform improvements themselves and get back to normal operations. Along with ARTEMIS there was an upgrade to the in-cab radio software [58].

The bandwidths for the GSM-R system were set by the European Union. The spectrum where GSM-R sits is next to that of the 3 and $4 \mathrm{G}$ signals and, because GSM is older technology, it becomes distorted by the 3/4G signals (P.B Personal Communication). A solution to this was made by the Network Rail Telecoms (NRT) but was expensive, and in the end, none of the stakeholders agreed to pay (C.B Personal Communication).

There had been a lack of delivery focus, which can be attributed to the initial design and plan of the roll-out, which caused some of the issues and problems experienced (P.B Personal Communication), along with a poor focus on what the future requirements of GSM-R might be. The future of GSM-R is to ensure that all the requirements for ETCS Level 3 can be met (C.B Personal Communication). Some functions have been added to the system ad hoc, such as the Caution Acknowledge function (P.B Personal Communication). Many of the programme managers focused on delivering the minimum required, and therefore did not concern themselves with future plans or the rollout strategy (C.B Personal Communication). Digital Rail has subsequently been set up to tackle such issues relating to GSM-R technology. There are difficulties that arose from the lack of future focus and meant some new developments incurred additional costs, with more work necessary (C.B Personal 
Communication). They were, however, able to build on a lot of the infrastructure laid out, such as the fibre optic cables installed [59].

\subsubsection{Stakeholder management}

After completion of the trials in Europe, a Memorandum of Understanding (MoU) was drafted in 1998. This committed the railways across Europe to stop investment in analogue radios and to only concentrate on GSM-R [17]. It also stated that early implementers would help other railways start through the exchange of knowledge and experience. At the time of introduction, 32 railways signed this $\mathrm{MoU}$ and, at the time of writing, a total of 37 railway institutions have signed, including some outside Europe [50]. Complimentary to the MoU was an Agreement on Implementation (AoI). This agreement meant that countries were committed to starting the implementation of GSM-R by 2003 [55].

The working groups created after the MoU in Europe were the ERIG (European Radio Implementation Group), Pre Q (GSM-R Pre-Qualification Group), FG (Functional Group) and OG (Operators Group) [17]. These groups met regularly to discuss system and functional requirements along with implementation issues. The groups have been replaced by the ERIG, which is now responsible for the EIRENE specifications and implementation activities [17]. The number of attendees to an ERIG group has slowly dropped, with around 15-20 members per meeting (D.M Personal Communication) compared to the 32 at the beginning. This is most likely as a result of the decreased interest in GSM-R implementation as members have installed GSM-R to their networks.

The ERIG representative from Network Rail would report back to the Association of Train Operating Companies (ATOC), now superseded by the Rail Delivery Group (RDG), which would then filter any information necessary to train operators (D.M Personal Communication). ATOC would also be involved in 8-weekly meetings, where Network Rail, ROSCO's, and train operators, would discuss GSM-R related activity and current issues (P.B Personal Communication).

Network Rail adopted a 'brute force' approach to implementation for this project, imposing a lot of the decisions onto the stakeholders. From certain points of view, it is easy to see how this approach was not inclusive (H.C Personal Communication).

Stakeholder strategies were applied successfully during the trials in Strathclyde. An example of this was a problem called misrouted calls, where a call from a driver is connected to a signaller that does not control that area [60]. This had not been seen before, as with the nature of trials, and was not fully understood. Scot-Rail, the train operating company taking part in the trials, was extremely concerned and nervous that the Strathclyde track was going to fail, subsequently, threatening to pull the plug on the trial. Network Rail was open and honest with Scot-Rail about the problem, creating trust which assured Scot-Rail that Network Rail were in control of the situation [57], allowing the trial to continue. 
Network Rail first informed most of the stakeholders about the implementation of GSM-R with a 'Network Change' document, which was sent out in 2005 (H.C Personal Communication). Network Rail conducted proficient stakeholder management, organising the network change framework documentation and ensuring all stakeholders were involved in this process (H.C Personal Communication). However, the initial Network Rail contact with stakeholders was a little erratic at first and the project team went through several iterations of organisational structure until a governance was agreed, with a number of project directors being replaced during this process (P.B Personal Communication).

Some operators felt that the notice they were given before becoming involved in the project was not soon enough (K.V Personal Communication). However, there are arguments against early engagement in such an environment, some stakeholders will ignore the information given to them as it is viewed too soon to be of concern to them (P.B Personal Communication).

It is clear there are many external stakeholders for the rail industry. However, every project is unique and has potentially unseen stakeholders that could cause issues with a project. One group of these stakeholders in the GSM-R project are public mobile phone companies. This is because the bandwidth used for both systems are very close to one another (P.B Personal Communication). To solve problems with interference, engagement was undertaken with the private mobile phone companies with great success. Adjusting things as the project moved forward, they could keep problems to a minimum (P.B Personal Communication). This was welcomed as the potential solution to the interference problem, as the solution put forward by the NRT would have been costly, with many of the external stakeholders refusing to pay for any upgrade (C.B Personal Communication).

Once the initial project was completed, the Network Rail project team closed down (K.V Personal Communication). This is understandable, as it is necessary to move on and stop funding once the project is completed (H.C Personal Communication). However, this had knock on effects to some external stakeholders, as for many, the project was still not complete. Network Rail did identify outstanding actions and assigned persons to deal with them (H.C Personal Communication), but in many cases this was not the same person that had been previously dealing with it. Therefore, communication between stakeholders and Network Rail began to break down, which in turn caused some stakeholders to neglect managing their side of the project (P.B Personal Communication) decreasing their participation.

\subsubsection{Human factors}

Human Factors research conducted for GSM-R was mainly focused on the location of the cab equipment [47, 48]. Human factors rarely explore human behaviour in adoption and implementation, especially in technological innovations. However, social behaviours [63], and the reaction to change, is an important success criterion for implementing research and technology [14]. 
In recent years, Network Rail have had a focus on human factors, with many associated objectives, mainly focusing on the interaction between humans and machine [64]. Human factor studies conducted during the trials in the Scottish Highlands created a guide for the positioning of the GSM-R equipment in the cabs [61]. However, this was hindered as a result of the retro-fitment onto older rolling stock, which has limited space. This meant that there were only a few fitment locations available and so, were unable to follow the human factor guidelines properly (K.V Personal Communication).

The organisational structure of the project within Network Rail meant that it was centrally managed. After the trials, there was a large organisational change (P.B Personal Communication), brought about because of the lessons learnt from the trials (P.B Personal Communication). After several iterations, the organisational structure emerged, as shown in Figure 4.

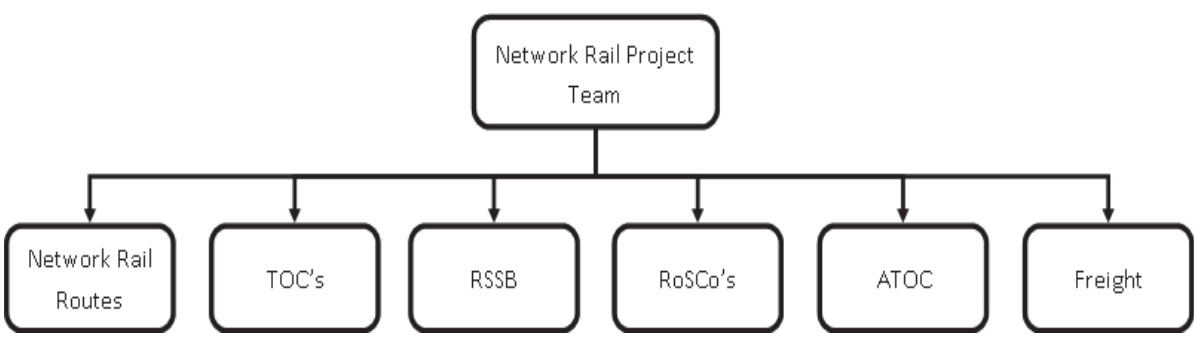

Figure 4: GSM-R Project Organisational Structure (P.B Personal Communication)

Figure 4 shows the Industry project team, whose role was to ensure that activities were properly managed, which proved effective (P.B Personal Communication). However, this is a very high level depiction of the structure used in the project. Each stakeholder had their own structure, which had the potential to be ineffective ( $P . B$ Personal Communication). Stakeholders, such as train operators, although on the surface may seem to have many employees, do not have the resources to form such project teams, and with other priorities and contractual commitments to running an operational service, were unable to spend endless time on projects (K.V Personal Communication).

The better performing stakeholders on the project had someone within their structure who had a lot of experience of GSM-R and understood what was necessary to deliver the project tasks and activities (P.B Personal Communication).

Once Network Rail closed the programme, the outstanding activities were passed onto the regional management teams known as Routes. With poor documentation of work and key people lost, activities relied heavily on the competence and enthusiasm of individuals rather than a set organisational structure to systematically manage the project deliverables (P.B Personal Communication). This is important for implementation success, as their attitudes can rub off on others and cause more 
individuals to work harder and collaborate with greater success (P.B Personal Communication).

Within complex industries, such as the railway, dictating to stakeholders, who have a tendency to resist, can create problems, which was no different in the implementation of GSM-R. Many of the stakeholders felt dictated to and therefore rebuffed any of the requirements put forward by Network Rail, making the decision process longer than it should have taken (H.C Personal Communication).

For the project to be a success, the stakeholders were required to conduct some of the implementation themselves. There was a mixture of attitudes among stakeholders, which meant some were more proactive than others (P.B Personal Communication). For example, the training of drivers - TOC's were required to liaise and consult employees to organise when they could be trained (K.V Personal Communication). This required a strategic approach, as certain parts of routes would not go live until certain times. Organising a timeline for when the training was carried out and who was to undergo training, so that drivers would be able to use the new system and keep themselves familiarised without the need to be re-trained later (K.V Personal Communication). Some train operators did this and some didn't, which meant the costs rose (K.V Personal Communication). The attitude to the additional cost was, as they weren't paying for it, it did not matter (K.V Personal Communication). The training was a standardised programme and went through every detail of the system. However, on reflection it may have been better to focus on the essential details (P.B Personal Communication). At the start of the project the rail industry did not fully understand the technology, it is, therefore, difficult to design and implement a training package when you do not know the emerging properties (P.B Personal Communication). Questions were asked, such as: 'Is the system intuitive enough' and, 'Was the training focused on the right area'? (P.B Personal Communication). Other emerging properties from the technology difficult to plan for were the behaviours of those using the technology. An example of this is where drivers did not input the train headcodes (a specific code used to identify the train in the signalling system) into the radio when doing short movements, e.g. moving into the sidings. Headcodes for such movements are seen by some as 'not worth it' (P.B Personal Communication). Although this does not cause an immediate safety risk, this behaviour was not expected and can cause problems for signallers not knowing the location of certain trains (P.B Personal Communication).

\section{Discussion}

This study shows that the implementation of research in to the rail industry is complicated with many features that make the process difficult to achieve. Similar to Palacin et al. [28], many of the barriers identified can be attributed to the three focal points of technology management, stakeholder management, and human factors outlined in this study. This demonstrates that the three focal points that form the base of this study can be considered an accurate portrayal of implementation in the rail industry. Analysing the data gathered from each of the three focal points outlines 
where they differ and what effects they had on the outcomes of the projects, it shows how each of the three focal points interact and affect one another.

Comparing how the research progressed between the two topics, TPWS is similar to the success stories from other industries, such as renewable energy [20], in that government legislation aided the development and implementation, and was therefore operational on time. Compare that to GSM-R, which did not have such strong governmental backing, took longer to develop and longer to implement. EU initiatives make this more complex, as it requires the co-ordination and agreement of multiple countries, before the complexities of each individual country can be considered. GSM-R is a different technology and undoubtedly more complex, as well as a requirement for the roll-out to be synchronised, the time taken was extremely long. The research carried out in Europe by other countries and railway institutions made the whole project more complex and made the tracking of research difficult. Once the research and development of the technology was completed, the implementation in the UK slowed down as a result of the details missed around the three focal points of this study: technology management; stakeholder management; and human factors. This discussion aims to compare the cases and to identify how each of the three focal factors of the study affect each other and can either facilitate or disturb the implementation of a technology.

Both projects went through the same basic processes of design, testing, and implementation. However, they differed in principles pertaining to each process. For example, each project trialled the technology, yet the results of the trials were acted on differently. The better the trial, the better potential for successful implementation. The roll out plans established for each project differed as a result of the type of technology being implemented. TPWS was a bespoke rail industry project and GSM$\mathrm{R}$ in tandem with different internal and external stakeholders and used an already established technology. This meant GSM-R should have been a simpler project but, arising from the complexities of the stakeholders involved, additional time had to be taken for the implementation. This shows that using 'off the shelf' technologies do not necessarily constitute a simpler project, and shows how invaluable the stakeholder management is in such large complex projects. Poor technology management in the form of not anticipating issues relating to the age of the rolling stock in the GSM-R project, meant there was a lack of locations for installing the in-cab equipment. This had knock-on effects to stakeholder management and human behaviour factors. Locations for TPWS, in comparison, were based on the human factor studies and, therefore, did not incur any resistance from stakeholders or end users. This shows that when industry has an interest in, and is acting upon, research, this can reduce the barriers to implementation faced later in the project.

The stakeholder approach used in implementing TPWS meant that the project became 'siloed'. This occurs when individual groups working towards a common goal become segregated and start working individually. Prompting their work to be carried out in their best interest, not in the best interest of the whole project or industry. Communication between the implementing partners became disjointed, although this 
was tied together by the turnkey contractor doing most of the work to the infrastructure and trains. Whereas, with the GSM-R project, many siloed divisions resulted and, because of the complexity with the stakeholders and the simultaneous nature of the roll-out plan, the ability to communicate and work together directly affected the success of the project. On the GSM-R project, some stakeholders had a certain individual with strong technical expertise on GSM-R to aid them with the complex items in the technology. This individual could make decisions, without the need to consult others and, therefore, the technical expertise of stakeholders determined how proactive and advantageous to the project a stakeholder could be. With a more technically complex project, this paper has shown that there is a need to reduce the inherent complexity in such a project by having clearer stakeholder communications, and by reducing the amount of 'siloes' which occur. This ensures that complex rollout plans, such as that found in the GSM-R case study, are conducted with greater efficiency.

It is important to keep relationships positive between stakeholders in the industries similar to the UK rail industry, especially when trying to co-ordinate an industry wide project. The trust between stakeholders in the UK rail industry has, for many years, been a balancing act, as they are in competition and collaboration at the same time. This makes research and data sharing a complex issue, and can hinder the development of technologies as there may not be the openness that is required as a lot of information is confidential. Such trust issues hindered the evaluation of GSM-R and prevented the admission of additional benefits that the system provided, as payments to Network Rail could have been required by the stakeholders. This caused the real benefits being found from the technology, as well as any knowledge from the implementation process itself, being gained.

TPWS was always a solution that was expected to be replaced after a certain amount of time, thus future development opportunities were not considered in the design of the system. Whereas, GSM-R's future focus created problems shortly after implementation, impacting the usefulness of the technology. Ensuring that a future focus is thought of early in the development, and not just the implementation, will ensure that the technology, or its use, is future proofed. To make this happen, a proper technology roadmap, that is agreed by all stakeholders, is required.

Although both projects had an organisational structure in place, designed to make the communication element between stakeholders better (Figures 2 \& 4), GSM-R's was more robust and tested. However, the organisational structure put in place for TPWS was simpler, and had fewer interacting bodies and, arising from the legislative action forcing TPWS to be implemented, the ability for stakeholders to resist the TPWS change was much lower than the GSM-R project. The organisational structures put in place, such as the Industry Project Team for GSM-R and the ROSCO's collaboration for TPWS, were made to make the implementation easier and smoother, there were certain stakeholders that do not have the resources to apply that amount of time into a project, particularly when their workforce is focused and used for their daily operations. When a change is imposed on an already tightly run 
stakeholder, resistance to change runs a much higher risk. This creates resistance and the adoption rates of such stakeholders is reduced, as the incentive to implement or take on such change is not justified, this was seen by the strong resistance found in the GSM-R project. Understanding resource constraints, and perhaps offering expertise to appease stakeholders, will increase their desire and contribution towards a project, while reducing the resistance to change. Change management techniques in technology implementation have been expansively studied in a range of industries such as Enterprise Resource Planning [23], where the main aim here is to reduce the amount of resistance from the stakeholders.

\section{Overcoming the barriers of implementation}

The strategy for implementing research and technology, and bridging the gap between research and industry is not as easy as speaking with the right people and developing a good product or service. The complexities of the UK rail industry mean that many other factors need consideration and detailed project planning is required, even at research level.

This paper has shown that for research uptake to increase, a higher management level and earlier level of interest by the industry is required in what is being done in the academic environment. This is also true of the academic environment, a higher level of interest in industry is needed, as well as the willingness to proceed and work with industry through the project, from initial research through to final implementation and project review.

From the results of this paper, Figure 5 has been developed to show the current and potential state of research progression and how to increase the adoption potential of research in the UK rail industry. As knowledge builds so does the industry's interest, however, currently, the industry's interest peaks later in the research cycle, meaning that either the research is no longer suitable for industry use, or the research may have been stopped arising from the lack of interest to take it forward. Figure 5 shows that if there is an increase in the industries interest, then the potential for adoption increases, with 'quick wins' being spotted and exploited by industry during the research cycle.

By increasing the industry's interest in research earlier in the research cycle, this can ensure the outcome of the research is tailored to the specific industry's needs. This will result in many of the academic works of literature that are very specific to an industry, being more transferable, and ensuring that when the research reaches a certain level, it can be used straight away, either by the industry or by a supplier for the industry. There is also an argument for the ability to achieve quick wins from this process, where industry representatives may find alternative and immediate uses for the research.

Collaborative working between industry and academia is required to build the knowledge base on a subject quickly, as described by Hameri [5]. It also requires the 
industry to be more involved for their interests to be exploited earlier. Both GSM-R and TPWS were industry-led projects and used suppliers to conduct most of the development. But, GSM-R was implemented so slowly that the interest from those who were to implement and use it arrived late affecting the successful outcome of the whole project. This, therefore, is also an argument for early engagement, especially with projects of such size and complexity. If stakeholders are involved early it can reduce the complexity and 'resistance' further into the project and engage the interest of the potential end users earlier. Project leaders and stakeholders who struggled to build relationships, or neglected the need to build relationships, found this much harder.

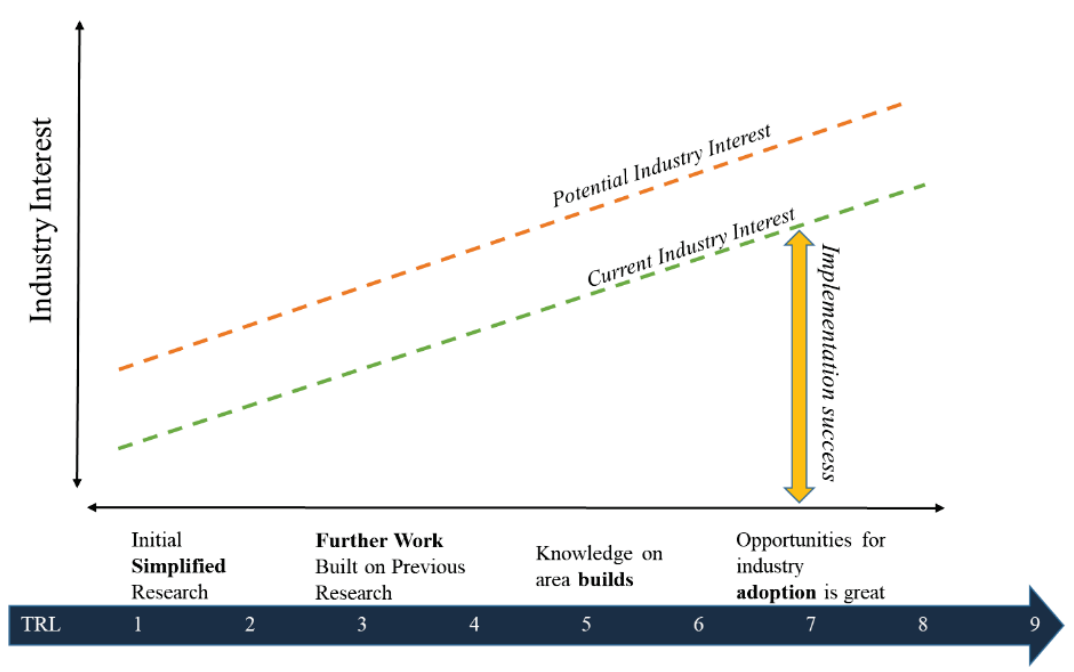

Figure 5. Current state of research adoption and possible future state

In a complex stakeholder industry, such as the UK rail industry, understanding the resources available to the stakeholders that are required to implement is important, just as asking or demanding such time involvement to a project that may not have immediate benefits will create resistance and cause projects to drag on over time. If possible, using a centralised project team, which can add resources to such organisations, may reduce stakeholder resistance, and, reducing the amount of time taken to implement the project, will increase the successfulness of the technology implementation.

\section{Study Limitations}

The method used in this paper analysed how the literature progressed and what research was carried out to develop the respective technologies. Published literature or formal reports were used in this review. However, with the potential for unpublished or inaccessible material to have influenced the research progression, it is 
understood that this may not portray an accurate representation. Mitigation for this is in the form of the interviews to understand the full picture of the two projects. The persons interviewed covered many of the typical stakeholders found in the projects and their questions based on their experiences. Work was carried out to make the questions as suitable as possible, but it was likely that some questions were not known by the interviewee. The semi-structured nature of the interview meant that questions could be changed to suit.

Limitations were found in the TPWS project arising from its age, similarly to Palacin et al. [28], much of the literature in databases came after 1990 with the invention of the internet, paperless documentation, and privatisation of the UK railways. Therefore, some studies may have been excluded because of this. Some of the persons involved in the TPWS project may no longer be working in the industry, meaning that some relevant information was missed, this was mitigated in the method by the inclusion of the second, more recent case study of GSM-R.

\section{Conclusion}

This paper has shown that creating a structure to an ad hoc problem is a difficult task. The method taken in this paper to create a structure considered the different views of persons involved in the implementation of the technologies and reviewed the links between research studies and implementation success.

Collaborative working between industry and academia is required to build the knowledge base on a subject quickly, as described by Hameri [5]. It also requires the industry to be more involved for their particular interests to be exploited earlier. Both GSM-R and TPWS were industry-led projects and used suppliers to conduct most of the development. But, GSM-R was implemented so slowly that the interest from those who were to implement and use it arrived late affecting the successful outcome of the whole project. This, therefore, is also an argument for early engagement, especially with projects of such size and complexity. If stakeholders are involved early it can reduce the complexity and 'resistance' further into the project and engage the interest of the potential end users earlier. Project leaders and stakeholders who struggled to build relationships, or neglected the need to build relationships, found this much harder.

Understanding how the three factors investigated in this paper link, and how they have a positive and negative effect on each other, can aid the implementation of research and technology. Making sure that these aspects are planned and executed correctly will ensure that potential problems do not occur or are well mitigated. Each of the three perspectives taken in this study interlink, where, if an incidence occurs in one, it will cause a reaction of sorts in another.

This paper has found through the two case studies that, to implement industry wide projects, a more phased approach may generate better results in terms of greater participation, less resistance, and a better product. It also allows confidence in a 
product to grow over time. In such a risk-averse and safety conscious industry, confidence in a product is paramount to achieve implementation success. This study has shown that to increase confidence, earlier interest in the research and a fundamental understanding of the technology can achieve this.

To increase the uptake of technology in the rail industry it has been found that overall interest and knowledge of forthcoming technologies by the industry is required. The problem that the rail industry has in this area is the longevity in which the stakeholders view the railway. Many stakeholders hold an operational and profit based perspective, looking short term arising from franchise lengths. Whereas infrastructure managers, such as Network Rail, have a longer-term view and longterm goals beyond those of some stakeholders. These differing goals and agendas of stakeholders can have a detrimental effect on the successfulness of complex industry wide projects, which creates a perception of risk when deciding to participate in or implement new research and technologies.

To do this, there is a greater need to understand the complexities of the rail industry and the connectivity of the three focal points of this study. How they affect each other, and how an action in one area will incur or require a reaction in another.

The method used in this study brings together the two perspectives of both academia and industry to find common ground. This method can be exploited by future research to understand how the gap between research and industry can be bridged. The case study approach provides a platform for the data to be presented and gives structure to a complex scenario. Future studies of complex environments can adopt this approach to simplify the problem.

\section{References}

[1] Department for Transport, "Delivering a Sustainable Railway (Rail White Paper)," 2007.

[2] UIC, Rail technical Strategy Europe. 2014.

[3] TSLG, "Rail Technical Strategy 2012," 2012.

[4] R. G. Tabak, E. C. Khoong, D. A. Chambers, and R. C. Brownson, "Bridging Research and Practice: Models for Dissemination and Implementation Research," Am. J. Prev. Med., vol. 43, no. 3, pp. 337-350, 2012.

[5] A.-P. Hameri, "Technology transfer between basic research and industry," Technovation, vol. 16, no. 2, pp. 51-92, Feb. 1996.

[6] P. Sind-Prunier, "Bridging the Research/Practice Gap: Human Factors Practitioners' Opportunity for Input to Define Research for the Rest of the Decade," Proc. Hum. Factors Ergon. Soc. Annu. Meet., vol. 40, no. 17, pp. 865$867,1996$.

[7] A. Wandersman, J. Duffy, P. Flaspohler, R. Noonan, K. Lubell, L. Stillman, M. Blachman, R. Dunville, and J. Saul, "Bridging the Gap Between Prevention Research and Practice: The Interactive Systems Framework for Dissemination and Implementation," Am. J. Community Psychol., vol. 41, no. 3-4, pp. 171- 
$181,2008$.

[8] E. Thompson, T. Kazi, and A. Scott, "Bridging the Gap Between Technology and Adoption: A Case Study," no. Dmi, pp. 1-8, 2011.

[9] P. Underwood and P. Waterson, "Systemic accident analysis: Examining the gap between research and practice," Accid. Anal. Prev., vol. 55, pp. 154-164, 2013.

[10] T. Greenhalgh, G. Roberts, F. MacFarlane, P. Bate, and O. Kyriakidou, "Diffusion of Innovations in Service Organizations: Systematic Review and Recommendations," Milkbank Q., vol. 82, no. 4, pp. 581-629, 2004.

[11] M. P. Eccles and B. S. Mittman, "Welcome to Implementation Science," Implement. Sci., vol. 1, no. 1, p. 1, Dec. 2006.

[12] M. Walsh, "Perceptions of barriers to implementing research," Nurs. Stand., vol. 11, no. 19, pp. 34-37, Jan. 1997.

[13] R. Salinas, P. Garner, R. Kale, R. Dickson, T. Dans, and R. Salinas, "Implementing research findings in developing countries," BMJ. Br. Med. J., vol. 317, no. 7157, 1998.

[14] J. Barlow, S. Bayer, and R. Curry, "Implementing complex innovations in fluid multi-stakeholder environments: Experiences of 'telecare,"' Technovation, vol. 26, no. 3, pp. 396-406, 2006.

[15] V. Peansupap and D. H. T. Walker, "Factors Enabling Information and Communication Technology Diffusion and Actual Implementation in Construction Organisations," vol. 10, no. July, pp. 193-218, 2005.

[16] C. Cannon, "Implementing Research Practices," High Sch. J., vol. 89, no. 4, p. 13, 2006.

[17] L. Pushparatnam, T. Taylor, K. Konrad, D. Mandoc, and G. Dalton, "GSM-R Procurement and Implementation Guide," 2009.

[18] P. Beria, E. Quinet, G. De Rus, and C. Schulz, "A comparison of rail liberalisation levels across four European countries," RETREC, vol. 36, pp. 110 120, 2012.

[19] R. Mcadam, S. Hazlett, and C. Casey, "Performance management in the UK public sector: Addressing multiple stakeholder complexity," Int. J. Public Sect. Manag., vol. 18, no. 3, pp. 256-273, 2005.

[20] H. M. Liou, "Policies and legislation driving Taiwan's development of renewable energy," Renew. Sustain. Energy Rev., vol. 14, no. 7, pp. 1763-1781, Sep. 2010.

[21] S. Jacobsson and A. Johnson, "The diffusion of renewable energy technology: an analytical framework and key issues for research," Energy Policy, vol. 28, no. 9, pp. 625-640, Jul. 2000.

[22] Liang Zhang, M. K. O. Lee, Zhe Zhang, and P. Banerjee, "Critical success factors of enterprise resource planning systems implementation success in China," in 36th Annual Hawaii International Conference on System Sciences, 2003. Proceedings of the, 2003, p. 10 pp.

[23] A. M. Aladwani, "Change management stratergies for successful ERP implementation," 2005.

[24] D. M. Jaideep Motwani Manu Madan, A. Gunasekaran, "Successful Implementation of ERP projects: Evidence from two case studies," J. Prod. Econ., vol. 75, pp. 83-96, 2002. 
[25] C. J. Bamber, J. M. Sharp, and M. T. Hides, "Factors affecting successful implementation of total productive maintenance," J. Qual. Maint. Eng., vol. 5, no. 3, pp. 162-181, Sep. 1999.

[26] C. Nash and B. Matthews, "Implementing rail infrastructure charging reform barriers and possible means of overcoming them," 2001.

[27] J. R. Wilson, L. Cordiner, S. Nichols, L. Norton, N. Bristol, T. Clarke, and S. Roberts, "On the Right Track: Systematic Implementation of Ergonomics in Railway Network Control," Cogn. Technol. Work, vol. 3, no. 4, pp. 238-253, Dec. 2001.

[28] R. Palacin, D. Golightly, V. Ramdas, and N. Dadashi, "Evaluating the impact of rail research: Principles to maximise innovation uptake," Proc. Inst. Mech. Eng. Part F J. Rail Rapid Transit, vol. 230, no. 7, pp. 1673-1686, Sep. 2016.

[29] R. Welham, "The Best Practice for Research and Technology to be Implemented into the UK Rail Industry," in RRUKA Annual Conference, 2016.

[30] G. Baldini, I. Nai Fovino, M. Masera, M. Luise, V. Pellegrini, E. Bagagli, G. Rubino, R. Malangone, M. Stefano, and F. Senesi, “An early warning system for detecting GSM-R wireless interference in the high-speed railway infrastructure," Int. J. Crit. Infrastruct. Prot., vol. 3, no. 3, pp. 140-156, 2010.

[31] R. Kukafka, S. B. Johnson, A. Linfante, and J. P. Allegrante, "Grounding a new information technology implementation framework in behavioral science: a systematic analysis of the literature on IT use," J. Biomed. Inform., vol. 36, no. 3, pp. 218-227, Jun. 2003.

[32] Railway Group Standard, "AWS and TPWS Interface Requirements," 2015.

[33] Network Rail, "Step Change in Safety Delivered on Time and Under Budget," News Releases, 2003.

[34] BBC News, "UK Politics: Green light for rail safety system," Aug-1999.

[35] BBC News, "UK Politics: Train drivers threaten strike over safety," Oct-1999.

[36] RSSB, "The strategy for the Train Protection and Warning System (TPWS)," 2015.

[37] R. J. S. Wheldon, "SPAD Reduction and Mitigation - AWS / Train Stop / Red Speed Trap Functional Specification," 1995.

[38] J. Uff and T. R. H. L. Cullen, "The Joint Inquiry into Train Protection Systems," 2001.

[39] M. Clements, "Reducing the risk," 2009.

[40] RSSB and Thales, "Development and evaluation of improvements to the TPWS to mitigate reset and continue risk," 2007.

[41] RSSB, "Justifications of TPWS modifications identified in reset and continue research," 2009.

[42] A. Scott and H. Gibson, "Red means stop, doesn't it? A human factors trial of a UK train safety system driver-machine interface," Third Int. Conf. Rail Hum. Factors, 3rd to 5th March 2009 Lille, 2009.

[43] RSSB and University of Plymouth, "Train Protection and Warning System," 2010.

[44] Railway Technical Web Pages, "Train Protection in the UK," Railway Technical Web Pages 1998-2016.

[45] RSSB, "Understanding Human Factors a guide for the railway industry," 2008. 
[46] R. Welham and T. Fujiyama, "Technology Innovation Implementation: The Influencing Factors in a Stakeholder Complex Industry," J. Technol. Transf., 2016.

[47] Oxalis, "ERTMS in Brief," 2013.

[48] M. Nixon, "Fleet Fitment Guidance," 2010.

[49] Network Rail, "GSM-R Overview Guide."

[50] P. Moody, I. Maxwell, K. Reilly, and S. Roberts, "Developing an operational concept for GSM-R to support its safe implementation in the UK," World Congr. Railw. Res., pp. 1483-1486, 2003.

[51] R. . Watson, "Low Cost Radio Signalling Study -Interim Report," 1995.

[52] V. Manoni and G. Fortuzzi, "Merging Between Telecommunications and Signalling," 1997.

[53] M. Klingler, M. Szelag, and MORENE Consortium, "Electromagnetic disturbances produced by the sparks between pantograph and catenary on a GSM telecommunication antenna," 1997.

[54] M. Berbineau, W. Pirard, S. Cantena, A. Pizza, and MORANE Consortium, "Radio Transmission Tests on Voice and Data GSM Services on the MORANE German Railway Trial Site," 1997.

[55] UIC, "The way from the idea to GSM-R."

[56] G. Morrisroe, "Preparation for the rollout of the GB GSM-R system," in 3rd International Conference on Rail Human Factors, 2009, pp. 295-304.

[57] Network Rail, Delivering the FTN/GSM-R Programme. 2014.

[58] Network Rail, "Guide to the GSM-R System," 2007.

[59] Rail Technology Magazine, "Network Rail to roll out wireless FTNx network in six months," 2014.

[60] C. Fulford, P. Barrett, and G. Cooper, "ATOC Guidance Note - Managing GSM-R Train Radio," 2014.

[61] RSSB, "Human factors input to cab fitment of GSM-R for Strathclyde," 2005.

[62] RSSB and Davis Associates, "Providing human factors input to cab fitment of GSM-R (T352 Report)," 2005.

[63] A. D. F. Price and K. Chahal, "A strategic framework for change management," Constr. Manag. Econ., vol. 24, no. 3, pp. 237-251, 2006.

[64] J. R. Wilson and B. J. Norris, "Rail human factors: Past, present and future," Appl. Ergon., vol. 36, no. 6 SPEC. ISS., pp. 649-660, 2005. 